Federal Reserve Bank of Minneapolis

Research Department

\title{
Business Cycle Research: \\ Methods and Problems
}

\author{
Edward C. Prescott \\ Working Paper 590 \\ Revised October 1998
}

*Prescott, The University of Chicago and the Federal Reserve Bank of Minneapolis. Prepared for the International School of Economic Research's XI Workshop, "Cycle, Growth and Technological Change." June 29, 1998, to July 7, 1998. Certosa di Pontignano-Siena (Italy). I thank Dirk Krueger and Jessica Tjornhom for useful comments and assistance in preparing the list of references. The views expressed herein are those of the author and not necessarily those of the Federal Reserve Bank of Minneapolis or the Federal Reserve System. 


\section{Part I: Methods in Business Cycle Theory}

\section{Introduction}

Basketball and soccer are different games. The objective is the same, namely to put the ball in the net. In both games, a ball is dribbled and passed. However, what is good dribbling and passing practice when playing one game is bad practice when playing the other. A soccer player who picks up the ball and bounces it as he runs down the field is not following good practice. This activity, however, is good practice when playing basketball.

In scientific inference there are two fundamentally different and complimentary games. The objective of both is the same, namely to draw scientific inference. One game is drawing deductive inference. The other game is drawing inductive inference. Both require the selection of a model. In this way they are similar. However, the rules for selecting the model are fundamentally different in these games.

This distinction between inductive and deductive scientific inference is important in business cycle research. Business cycle theory uses deductive or quantitative theoretic inference. Often practitioners do it poorly. They do it poorly because they use practices that are good for inductive inference but bad for deductive inference. Their behavior is analogous to the soccer player who picks up the ball and bounces it as he runs down the field.

I first clarify the differences between these forms of scientific inference. I do this by reviewing the role played by each in the development of the natural sciences.

With inductive or empirical inference the product is the model or the law. In physics an example of inductive inference is Kepler's laws of planetary motion. These laws are:

Law 1: Planets follow an elliptical orbit around the sun, 
Law 2: The sun is at one of the foci of each ellipse,

Law 3: An equal area of a planet's ellipse is swept out in a given time interval by the planet.

Another example of successful inductive inferences in the natural sciences is Galileo's discovery of the law of motion or model of a ball rolling down an incline plane. This law is:

$$
\mathrm{D}=1 / 2 \mathrm{~g} \sin (\theta) \mathrm{t}^{2}
$$

where $\mathrm{D}$ is distance, $\mathrm{t}$ is time, $\theta$ is the angle of the inclined plane, and $\mathrm{g}$ is a constant. An important feature of the formula is that the weight of the ball does not appear. I do not use the term mass as that concept did not exist when Galileo discovered his law. The concept of mass had meaning only subsequent to the development of Newton's theory of mechanics.

Inductive or empirical inference was productive in the natural sciences. Good inductive practices involved model estimation and testing. This raises the question of why inductive or empirical inference proved sterile in business cycle research. This sterility was not due to the incompetence of the researchers who pursued the inductive approach. The group who pursued this research program included a disproportionate number of the best minds in economics. The reason these inductive attempts failed, I think, is that the existence of policy invariant laws governing the evolution of an economic system is inconsistent with dynamic economic theory. This point is made forcefully in Lucas' famous critique of econometric policy evaluation.

With deductive inference a model is a tool or measurement instrument used to deduce the implication of theory. This statement requires a discussion of what theory is. The definition that I will use is an implicit set of instructions for constructing a model economy for the purpose of answering a question. Two examples of theory drawn from physics are: (i) Newtonian Mechanics - force equals mass times acceleration - and (ii) Newton's Universal Law of Gravitation- 
the gravitational force operating on two bodies is proportional to the product of the masses and inversely proportional to the square of the distance. These theories provide a theoretical foundation for Kepler's laws of planetary motion and Galileo's law of a ball rolling down an inclined plane. Newtonian mechanics has proven useful. This theory is used to construct models for all kinds of purposes in the engineering sciences. It is used to predict the path of rocket ships and to control their paths. It is used to design machinery in factories.

In economics there is Walrasian general equilibrium theory, which Schumpeter (1954) judged to be "the only work by an economist that will stand comparison with the achievements of theoretical physics." I do not agree with the "only" part of Schumpeter's statement, as I would add Arrow-Debreu general equilibrium theory to this list, and possibly game theory and the closely related mechanism design theory.

General equilibrium theory is theory in the language sense but not in the sense that I am using the word theory. The reason is that without restrictions on preferences and technology general equilibrium theory is virtually vacuous. Consequently it is not a set of instructions for constructing an instrument to measure something or predict the consequences of some policy. Growth theory with measures of the elasticity of substitutions and transformations and share parameters is theory in the sense I am using it here. Growth theory provides instructions for constructing a model economy to address some question of interest. The quantitative answer to the question is deduced for the model economy. In business cycle studies, growth theory is the theory used. Indeed, business cycle research is largely drawing inference from growth theory for business cycle fluctuations. Growth theory is also heavily used to construct models to estimate the welfare and other quantitative effects of tax policies and social security systems. 
In this review I will explain why using estimation theory to select a model used in drawing deductive inference is bad practice. Unfortunately, or maybe fortunately for economists, there is no set of mechanical rules for selecting a good model for deducing some inference of a theory. I say it may be fortunate because, if it were mechanical, computers could replace economists. I now illustrate this point by reviewing the development of modern business cycle theory.

\section{History and Overview of Business Cycle Theory}

Burns and Mitchell (1946) developed a statistical definition of a business cycle. This definition did not prove useful. Kuznets and his students were more successful. They systematically reported economic events using a system of national income and product accounts. They also reported aggregate factor inputs of capital and labor. A set of growth facts emerged from this reporting. These facts guided researchers in the development of growth theory. Some of these facts are as follows. Labor share of product, using Kravis' (1959) economy-wide assumption, is more or less constant over time even though the real wage increased dramatically relative to the rental price of capital. Subsequently Gollin (1997) found that this regularity held across countries with deviations being unrelated to the level of development. Another fact is that the investment share of product is more or less constant. This led to the Solow growth model with a Cobb-Douglas aggregate production function. The Solow model with its aggregate production function and factors being paid their marginal product is a theory of the income side of the national income and product accounts.

The Solow growth model, with its exogenously determined savings rate, led the economic theorists Cass (1965), Koopmans (1965) and Diamond (1965) to develop a theory of the allocation of product between consumption and investment. Brock and Mirman (1972) extended this theory to stochastic environments. 
Lucas (1977) defined business cycles to be recurrent fluctuations of output and employment about trend. He wrote that the key business facts were the comovements of the economic time series. Hodrick and I (1980) developed a statistical definition of the business cycle component of an economic time series. The regularities that appeared are all tied to the variables in growth theory. They are: (i) consumption is strongly procyclical and fluctuates about a third as much as output in percentage terms; (ii) investment is strongly procyclical and fluctuates about three times as much as output; (iii) two-thirds of output fluctuations are accounted for by variations in the labor input, one-third by variations in TFP and essentially zero by variations in the capital input; (iv) the only important lead-lag relation is that the capital stock lags the cycle with the lag being greater the more durable the capital good; (v) the deviations of output from trend, that is the business cycle component, displays a moderately high degree of persistence; (vi) the real wage is procyclical but is roughly orthogonal to the labor input.

These facts were bothersome for theorists. Why should leisure be low when consumption is high? After all, consumption and leisure are normal goods and leisure is not high when the real wage is high. Another question is why labor productivity is high when labor input is high. This violates the law of diminishing returns.

Many have argued that Hodrick and my facts are not interesting because we did not correctly measure the business cycle. This criticism is spurious. An operational definition can be neither right nor wrong and our definition is an operational definition. Economics is not the only science where operational definitions have proven useful. In the natural sciences prior to the development of the theory of an ideal gas the definition of temperature was an operational one being neither right nor wrong. An environment was 50 degrees Celsius if the thermometer registers 
half way between what it registers when it is immerged in ice water and what it registers when immerged in boiling water.

In retrospect, Hodrick and my representation of time series as the sum of two components, one we called the growth or trend component and the other the business cycle or deviation component, turned out to be a useful one. Our representation revealed some behavior that was in apparent contradiction with theory and fostered the development of some good theory.

I emphasize that these facts were in apparent contraction with theory. Until the dynamic applied general equilibrium tools were developed to derive the implication of growth theory for business cycle fluctuations, economists had to rely on their intuition derived from price theory. This price theory intuition proved to be wrong.

Exploiting Arrow-Debreu language, recursive methods, and computational methods, Kydland and I (1982) derived the implications of growth theory for business cycle fluctuations. To our surprise we found that, if total factor productivity (TFP) shocks are persistent and of the right magnitude, business cycle fluctuations are what growth theory predicts. Subsequently I (1986) found that these TFP shocks are highly persistent and of a magnitude that implies that they are the major contributor to business cycle fluctuations. This success of growth theory led me to have greater confidence in public finance findings that use growth theory to evaluate tax policies.

Kydland and Prescott (1982) examine the consequence of people valuing leisure more if they have worked more in the past. The introduction of this feature into growth theory preserved the consistency of the theory with the growth facts. Its introduction increases the inter-temporal elasticity of substitution for leisure and results in the prediction of the model being more in conformity with aggregate observations. However, this feature should not be part of the measure- 
ment instrument used to answer the question of how volatile the U.S. economy would have been if TFP shocks were the only shocks until other evidence is provided that it indeed quantitatively describes people's preferences. Such evidence never materialized. This leads to the following two principles for selecting the model used in business cycle research.

Principle 1: When modifying the standard model of growth theory to address a business cycle question, the modification should continue to display the growth facts.

Principle 2: The model economy being used to measure something should not have a feature which is not supported by other evidence even if its introduction results in the model economy better mimicking reality.

When modifying the standard growth model to address a business cycle question, Hansen (1985) introduced another feature, a labor indivisibility, and permitted people to enter into mutually beneficial insurance contracts as in Arrow-Debreu theory. This increases the magnitude of the response to TFP shocks. There is empirical evidence that justifies incorporating of this feature. First, there is unemployment insurance and people have a close substitute for insurance, namely the holding of liquid assets. Second, and most important, most of the cyclical variation in the labor input is the result of variation in the number of people that work in a given week and not in the average workweek length. Like Kydland and my non time-separable utility function, the introduction of this feature results in leisure having a high intertemporal elasticity of substitution.

Hansen finds that for his model economy, cyclical fluctuations induced by technology shocks are as large as the observed fluctuations. Given the strong empirical support for labor indivisibility, this mechanism should be part of the model or measurement instrument used to answer the question of the importance of technology shocks for business cycle fluctuations. A 
problem, however, is that not all fluctuations in hours are the result of the variations in the number of people working. An important fraction is the result of variation in the workweek length as in Kydland and my model economy. This number is somewhere between the Hansen and the original Kydland and Prescott estimates.

What was needed was better theory. The reason is the following. Why is the workweek

fixed? If it is permitted to vary and aggregate hours is the labor input to production, then all work and all variation is in the workweek length. There was a major inconsistency between observation and theory. Better theory was developed that reduced this inconsistency. I begin with the aggregate production function and its inadequacy for the purpose of understanding the determination of workweek length.

\section{The Aggregate Production Function}

The aggregate production function with labor and capital as its inputs, which has proven so useful in public finance, fails to capture the intensity with which people and machines work. These intensities vary over the cycle. Before discussing how to extend the theory of the production function utilizing results of Mas-Colell (1975), Hart (1979), and Jones (1984) on differentiated commodities, the aggregation theory underlying the aggregate production function will be reviewed.

The technologies underlying the aggregate production function:

(i). There are $\mathrm{n}$ factor inputs and a composite output.

(ii). The vector of inputs is $x \in \mathfrak{R}_{+}^{n}$ and the output good is $\mathrm{y}$.

(iii). A plant technology is indexed by $x \in T$ with $\mathrm{f}(\mathrm{x})$ being plant type $\mathrm{x}$ output.

(iv) $\quad X \in \mathfrak{R}_{+}^{n}$ is the vector of aggregate inputs and $Y$ aggregate output. 
Definition: An aggregate production function $\mathrm{F}(\mathrm{X})$ is the maximum output that can be produced given the input vector $\mathrm{X}$.

Assumption 1: Any number of technologies of type $x \in T$ can be operated.

Assumption 2: For all $x \in T, \mathrm{x}$ is infinitesimal relative to $\mathrm{X}$.

Assumption 3: $T \subset \mathfrak{R}_{++}^{n}$ and $T$ is compact.

Assumption 4: $f: T \rightarrow \Re$ is continuous.

The aggregate production function is the solution to the following program, where $M_{+}(T)$ is the set of measures on the Borel sigma algebra of $\mathrm{T}$,

$$
\begin{gathered}
F(X)=\max _{z \in M_{+}(T)}\left\{\int f(x) z(d x)\right\} \\
\text { subject to } \int_{T} x_{i} z(d x) \leq X_{i} \quad i=1,2, \ldots, n .
\end{gathered}
$$

Given the assumptions, the constraint set is compact and non empty and the objective function is continuous in the weak star topology. Therefore the program has a solution. Two well-known results are the following.

Proposition: $F(X)$ is weakly increasing, continuous, weakly concave, and homogenous of degree one.

Proposition: If there is free entry, profit maximization results in output being maximized. 


\section{An Example:}

The Cobb-Douglas production function has come to dominate in aggregate applied general equilibrium analysis. The reason is that both over time and across countries, labor's share of product is surprisingly constant at 70 percent. ${ }^{1}$ The Cobb-Douglas production function, with its unit elasticity of substitution, is about the only aggregate production function with the property that factor income shares are the same even though relative factor prices are very different.

An example of an underlying set of plant technologies for the Cobb-Douglas production function is the following one. Suppose that the factor inputs are capital $\mathrm{k}$ and labor $\mathrm{n}$ and that the plant technologies are $\mathrm{g}(\mathrm{n}) \mathrm{k}^{\theta}$. In addition, the function $\mathrm{g}$ is such that the function $\mathrm{g}(\mathrm{n}) \mathrm{n}^{\theta-1}$ has a maximum. This maximum is denoted by $\mathrm{A}$ and a maximizing $\mathrm{n}$ by $\mathrm{n}$.

Proposition: For this example, the aggregate production function is

$$
\mathrm{F}(\mathrm{K}, \mathrm{N})=\mathrm{A} \mathrm{K}^{\theta} \mathrm{N}^{1-\theta}
$$

Outline of proof:

Given there are two constraints and an optimum exists, there is an optimum with at most two types of plants operated. Consider one such optimum. Let $\left(\mathrm{K}_{\mathrm{i}}, \mathrm{N}_{\mathrm{i}}\right)$ be the aggregate factor inputs used to operate type $\mathrm{i}$ plants for $\mathrm{i}=1,2$. Allocate $\left(\mathrm{K}_{\mathrm{i}}, \mathrm{N}_{\mathrm{i}}\right)$ equally to $\mathrm{m}$ plants of type $\left(\mathrm{K}_{\mathrm{i}} / \mathrm{m}, \mathrm{N}_{\mathrm{i}} / \mathrm{m}\right)$. The $\mathrm{m}$ for which $\mathrm{N}_{\mathrm{i}}=\mathrm{mn}^{*}$ is an optimum. Thus, all operated plants for this optimum have $n=n *$. Output maximization requires marginal products of capital be equated across operated plants. Thus, operating $\mathrm{N} / \mathrm{n}^{*}$ plants each with $\mathrm{n}^{*}$ workers and $\mathrm{K} /\left(\mathrm{N} / \mathrm{n}^{*}\right)$ units of capital is optimal. Using this result,

\footnotetext{
${ }^{1}$ See Gollin (1997) for the cross-country numbers. He uses the Kravis' (1959) economy-wide assumption for assigning proprietor's income and indirect business taxes to capital and labor.
} 


$$
F(K, N)=\frac{N}{n^{*}} g\left(n^{*}\right)\left(\frac{K}{N n^{*}}\right)=A N^{(1-\theta)} K^{\theta}
$$

\section{Workweek of Capital}

The workweek of capital and labor varies cyclically. The aggregate production function does not capture this. The following technologically does:

$$
\mathrm{y} \leq \mathrm{A} \mathrm{h} \mathrm{k}^{\theta}
$$

where $0<\theta<1$ and where $\mathrm{y}$ is the output produced by an individual, $\mathrm{k}$ is the capital that that individual uses and $\mathrm{h}$ is the length of that individual's workweek. Element $\mathrm{h}$ belongs to the set $\mathrm{H} \subset$ $(0,1]$.

Question: What is the aggregate production function for this technology?

A workweek of different length is a different factor input. Following the procedures above, there is an aggregate production function. The inputs are capital $\mathrm{K}$ and the measure $\mathrm{N} \in$ $\mathrm{M}(\mathrm{H}) . \mathrm{N}(\mathrm{B})$ is the measure of people working a workweek belonging to Borel measurable set B $\subseteq \mathrm{H}$. An aggregate production function $\mathrm{F}(\mathrm{K}, \mathrm{N})$ exists.

To simplify exposition I deal with the case that there are only a finite number of possible workweek lengths. Then $\mathrm{N}_{\mathrm{h}}$ is the measure of workweeks of length $\mathrm{h} \in \mathrm{H}$ and $\mathrm{N}$ is a finite dimensional vector. For each workweek length the aggregate production function is

$$
\mathrm{F}_{\mathrm{h}}\left(\mathrm{K}_{\mathrm{h}}, \mathrm{N}_{\mathrm{h}}\right)=\mathrm{h} \mathrm{A} K_{h}^{\theta} N_{h}^{1-\theta}
$$

The aggregate production function $\mathrm{F}(\mathrm{K}, \mathrm{N})$ is obtained by equating marginal products of capital across these aggregated technologies and summing over $h$.

Finn Kydland and I (1991) introduced this feature into the growth model. In our model economy households' preferences are ordered by the expected value of 


$$
\sum_{t=0}^{\infty} \beta^{t} \frac{\left[c_{t}^{1-\psi}\left(1-h_{t}\right)^{\psi}\right]^{1-\sigma}}{1-\sigma} .
$$

The technology parameter $\left\{A_{t}\right\}$ is governed by a first order auto regressive process with high persistence. Capital depreciates exponentially. The parameters are selected so that the model economy displays the growth facts including the rough constancy of the fraction of time allocated to the market, including commuting time.

Kydland and I were surprised that cyclically only the fraction of the population working varied and not hours per employed worker. Hornstein and I (1993) find that this is precisely what theory predicts. The fact that hours per worker do vary, however, is not bothersome for theory. Kydland and I (1991) find tiny costs of moving between the market and the household sector results in h varying cyclically, as it does.

Introducing this option to vary the length of the workweek along with some moving costs results in observations being in better conformity with theory. The costs are selected so that the relative variability of employment and workweek length match observations. The resulting model, or measuring instrument, is a better one than either Kydland and my original model or the Hansen model. Using this model Kydland and I estimated that the U.S. post war economy would have been 70 percent as volatile if total factor productivity shocks were the only disturbance. Here the volatility measure is the standard deviation of the business cycle component.

With this 70 percent number, an implication of theory is that labor productivity should be orthogonal to the labor input, as it is in the data. If the estimate contribution had been near 100 percent, an implication of theory is that labor productivity and the labor input should be highly correlated, as they are in the model economy. This leads to an important methodological point. Given this 70 percent estimate, if both the model and the actual economy had high correlation 
between labor productivity and the labor input, it would have been a basis for rejecting the model as a good instrument for measuring the importance of TFP shocks.

Principle 3: A model that better fits the data may be a worse measurement instrument. Indeed, a model matching the data on certain dimensions can be the basis for rejecting that model economy as being a useful instrument for estimating the quantity of interest.

Principle 4: A corollary of Principle 3 is that the using statistical estimation theory to estimate models used to deduct scientific inference is bad practice. Estimating the magnitude of a measurement instrument, whether it is a thermometer or a model economy makes no sense.

There are legitimate challenges to this 70 percent number. Challenging the result because the model used is not realistic is not one. As stated previously all models are abstractions and therefore unrealistic. A legitimate challenge is to introduce some feature into the model economy in a quantitatively reasonable way and show that the answer to the question changes. There have been many such challenges to Kydland and my finding, but the result has been found to be ro-

bust. Before proceeding with a review of some of these studies, I will state the fifth and last principle.

Principle 5: A legitimate challenge to a finding is to introduce a feature into the model economy that is serving as the measurement instrument in a quantitatively reasonable way and show the answer to the question changes.

\section{Robustness of Results to Increasing Returns and Monopolistic Competition}

Hornstein (1993) extends the neoclassical growth model to incorporate firm-specific monopolistic competition and increasing returns to scale. In his model world there is a large and fixed number of firms where each firm has market power for its own product. Increasing returns 
to scale at the firm level is introduced through a fixed cost to production. This assumption allows for an equilibrium where firms make profits but, on average, profits are zero.

To account for the role of productivity shocks as sources of output fluctuations Hornstein focuses on two effects. First, he studies to what extent the Solow residual overestimates actual productivity changes. Second, he demonstrates that, compared with the basic neoclassical growth model, a productivity shock generates a stronger output response and a weaker employment response. The change in output and employment responses can be attributed to the increasing returns to scale that also generates stronger wealth effects and thereby dampens employment fluctuations. Finally, he suggests that the net effect of increasing returns to scale and monopolistic competition is to lower the contribution of the productivity shocks to output fluctuations somewhat, but that this effect is limited when mark-ups and returns to scale are not unreasonably large. Cooley, Hansen and Prescott (1995) find similar results for a model economy with idle capital.

Devereux, Head and Lapham (1996) incorporate technology shocks into a real business cycle model with monopolistic competition and increasing returns to both specialization and scale. They find that market power and increasing returns due to fixed costs have no effect on the responses of aggregate variables to a technology shock when compared to those exhibited by a standard, perfectly competitive real business cycle model. The responses of aggregate variables to technology shocks are actually increased by returns to specialization and reduced by returns to scale in variable factors. They find that returns to specialization and scale also affect the measurement of technology shocks. The variance of the Solow residual understates the variance of the technology shock due to increasing returns to scale. Returns to specialization result in the opposite bias. When both type of increasing returns are present, the authors find the variance of 
output is increased relative to a standard competitive model despite a significant reduction of the variance of technology shocks.

Fagnart, Licandro and Portier (1997) investigate the phenomenon of under utilization of productive equipment and its implications for business cycles. The authors introduce the concept of capacity utilization (as opposed to capital utilization) into a stochastic dynamic general equilibrium model. Monopolistically competitive firms use a 'putty-clay' technology and decide on their productive capacity and technology under idiosyncratic (demand) uncertainty. It is shown that the proportion of firms with excess capacities plays an important role in magnifying and propagating aggregate (technological) shocks. Furthermore, they find that idiosyncratic uncertainty about the exact position of the demand curve faced by each firm explains why some productive capacities may remain idle in the sequel and why individual capacity utilization rates differ across firms. Finally, the variability of capacity utilization allows for a good description of some of the main stylized facts of the business cycle and generates endogenous persistence.

\section{Consequence of Capital and Capacity Utilization Variation for the Estimate}

Greenwood, Hercowitz and Huffman (1988) make the assumption that the intensity with which capital is used, say $\mathrm{x}$, is a choice variable. The amount of capital services is the product of $\mathrm{x}$ and $\mathrm{K}$. The cost of using capital more intensely is that depreciation is greater.

$$
K_{t+1}=(1-\delta(x)) K_{t}+I_{t} .
$$

The function $\delta(\mathrm{x})$ is increasing in $\mathrm{x}$.

Introducing this feature results in aggregate observations being in greater conformity with theory. However, there is a problem. The problem is the lack of micro observations to back up the depreciation assumption. Does capital depreciate more in boom periods? Until other evi- 
dence is provided for this depreciation assumption, this feature is best not incorporated into the measurement instrument.

\section{Labor hoarding over the business cycle}

Burnside, Eichenbaum, and Rebelo (1993) introduce the possibility of labor hoarding. In their model world, people must commit to how many hours they will work over the next three months. During this three month period only the worker's work intensity can vary. In fact hours of employment is not fixed for such long periods for much of the workforce. There are weekly layoffs and variations in the length of the workweek. Their analysis is important for it nicely puts to rest the labor hoarding story that has confused the profession for so many years. The paper accomplishes this by showing how extreme and implausible assumptions must be for labor hoarding to be a factor in understanding business cycle fluctuations. Labor hoarding is only important when shocks are temporary, not when they are highly persistent, and business cycles are responses to highly persistent shocks. 


\section{Part II: Problems in Business Cycle Theory}

\section{Introduction}

There is no shortage of important open problems in business cycle theory. What is in short supply are problems that are both important and analyzable using existing tools. My view is that whenever new tools are developed, it is a good time to search the set of important open problems for one that can be analyzed using these new tools. With this in mind I focus only on problems for which the needed tools have been recently developed or are being developed.

\section{The Role of Organizations in Business Cycles}

Fitzgerald (1998a, 1998b) develops and uses a general equilibrium framework in which the number of hours and the employment levels of heterogeneous workers is endogenously determined. He does this in an environment where production requires coordinating work schedules of different worker types, a characteristic that he refers to as team production. In particular, he assumes that all workers in a production team must work the same hours. Output is produced by a large number of teams, where team composition and the hours a team works can differ across teams.

He has two types of workers, the skilled and the unskilled. Skilled workers lose human capital if they are not employed. He finds that constraints on workweek length increase the welfare of the high income skilled people and reduce the welfare of the low income unskilled workers. Furthermore, he finds there is an increase in the employment rate of the unskilled workers. He also finds that introducing this realistic feature does not change the estimate of the importance of total factor productivity shocks for business cycle fluctuations. 
In the model he uses preferences that are additively separable in consumption and leisure, namely

$$
E\left\{\sum_{t=0}^{\infty} \beta^{t}\left[\log \left(c_{t}(s)\right)+v\left(1-h_{t}(s)\right)\right]\right\} .
$$

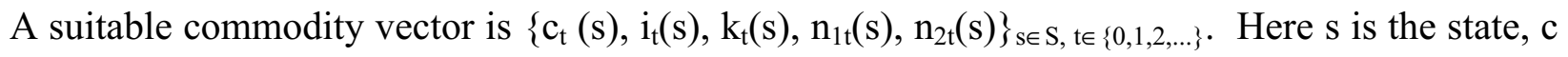
and $\mathrm{k}$ are scalars, and the $\mathrm{n}_{\mathrm{i}}$ are signed measures on the Borel sigma algebra of $[0,1]$. Restrictions on a type $i$ consumption set are that $n_{i}$ be a probability measure and $n_{j \neq i}$ be the null measure.

The plant production function is

$$
\mathrm{h} \mathrm{f}\left(\mathrm{k}, \mathrm{x}_{1}, \mathrm{x}_{2}\right)
$$

where $\mathrm{h}$ is hours the plant is operated, $\mathrm{k}$ is the capital employed and the $\mathrm{x}_{\mathrm{i}}$ are the number of type $\mathrm{i}$ workers. Suppressing the $\mathrm{t}$ and $\mathrm{s}$ index, a period aggregate production possibility set is

$$
\begin{aligned}
Y=\left\{\left(C, I, K, N_{1}, N_{2}\right) \geq 0 \mid \exists \text { measure } z\left(d h \times d k \times d x_{1} \times d x_{2}\right) \quad\right. \text { for which } \\
C+I \leq \int f\left(k, x_{1}, x_{2}\right) d z \\
\int k d z \leq K \\
\int_{\left\{\left(h, k, x_{1}, x_{2}\right) \mid x_{i} \in B\right\}} d z
\end{aligned}
$$

The set is a convex cone so there are constant returns to scale.

\section{The Role of Money in Business Cycles}

A question that has received a great deal of attention is whether monetary factors are a major contributing factor to business cycle fluctuations. Friedman and Schwartz (1963) argued in a comprehensive empirical study that monetary shocks are the major economic cause of business cycle fluctuations. They observed that sharp declines in the money stock occurred prior to severe economic downturns. 
The apparent inconsistencies of economic fluctuations with economic theory that abstracted from money led to widespread acceptance of the Friedman-Schwarz view even though a theoretical foundation was lacking. Real business cycle theory finds that a major fraction of US postwar business cycle fluctuations is accounted for by persistent shock to total factor productivity (see Kydland and Prescott (1991)). If money is not a major contributing factor to business cycle fluctuations, why is money highly correlated with output? Freeman and Kydland (1998) provide a possible answer using a transaction based theory of money. They introduce a costly transaction technology into the standard growth model and find that monetary aggregates and output are positively correlated even though there is no causal relationship between money and output.

An issue is how to model money. Currently the dominant view is that money is valued because it facilitates existing trade or permits new trade. Lucas (1980) and Lucas and Stokey (1987)) develop cash-credit goods and cash-in-advance models. Ireland (1995), Schreft (1992), Freeman and Kydland (1998)) develop transaction based models. Saving (1971) and McCallum and Goodfriend (1987) develop shopping time models. Christiano and Eichenbaum (1995), Fuerst (1992) and Scheinkman and Weiss (1986) develop and explore limited participation models.

A question is how do these transaction-based theories standup to the facts. At the very low frequencies their performance is impressive (see Lucas (1988)). At the very high frequencies there are no problems because, with Lucas surprises, these theories place weak restrictions on observations. At the intermediate frequencies, these theories with their empirical demand for money relations fail and fail spectacularly. These theories predict much larger variations in the demand for money than observed given the variation in the nominal interest rate. 
Whether this failure is a serious one for evaluating the importance of monetary shocks for business cycle fluctuations is an open issue. This question, however, is likely central for evaluation and design of monetary stabilization policies, which is the principal reason for developing a theory of money. Perhaps the empiricists are right that adopting a constant money growth rule will result in less fluctuations in output and employment. Perhaps they are wrong. Until there is some strong monetary theory the answer is unknown. Once there is the good theory for evaluating monetary policy, the welfare benefits and costs of alternative policy rules can be deduced.

Researchers using the RBC methodology and a transaction based theory of money have found that money contributes little to business cycle fluctuations. I, however, see these exercises as being far from conclusive in establishing that monetary policy can not be used to stabilize the economy. The reason is the failure of these theories at the intermediate frequencies. DiazGimenez, Prescott, Fitzgerald and Alvarez (1992) have taken an alternative approach that may not suffer from this deficiency. Key in their model is the government issuance of nominal debt that is held directly or indirectly by households. In the United States in 1986 they report that the outstanding stock of nominal debt is nearly one annual GNP. There is also large amount of lending by old to young in nominal terms to finance home purchases. Consequently there is a lot of risk associated with unexpected inflation that results in redistribution between young borrower and old lenders. A question is why markets do not develop to eliminate this risk. One answer is that there is no way for the unborn to contract with people alive to avoid the risk associated with this redistribution.

Another possibly important component of a successful theory for evaluating monetary policy rules is intermediation costs. These costs are large. In rich countries the spread between the average borrowing and average lending rates is about 5 percent. The total product of the fi- 
nancial sector is 9 percent in the United States in 1986. Still another possibly important component of a successful theory for evaluating monetary stabilization policy is moral hazard associated with allocating idiosyncratic risk. Empirically much of this idiosyncratic risk is not eliminated, which would be the case if financial markets were frictionless and there was a complete set of state contingent commodities.

\section{The Role of Policy in Determining Labor-Leisure Tine Allocation}

The Great Depression in the United States is an example of a large deviation from the neoclassical growth theory that is not accounted for by variations in TFP. In 1939 hours worked per adult were still 23 percent below what it was in 1929, the year prior to the start of the Great Depression. During this ten year period output per hour increased by about 10 percent, which is only a little below the historical average. The question is why employment didn't return to its 1929 level. The only candidate for an answer is policy that changed the nature of the game being played by the economic actors.

\section{International Business Cycles}

Backus, Kehoe and Kydland (1992) use theory to construct a model economy to derive the implications of growth theory for international business cycles. They assume, among other things, that there is a full set of state-contingent commodities. They find that observations deviate from the predictions of this theory in important respects. First, consumption between countries is less correlated between countries than theory predicts. Second, investment and labor supply are too negatively correlated with output.

Their findings led Baxter and Crucini (1995) and Kollmann (1996) to restrict international asset markets to just borrowing and lending. With this restriction, the model economy better mimics reality. But, the question of why there is this restriction is left unanswered. This 
led Kehoe and Perri (1998) to endogenize these debt contacts. They consider a model economy with limited enforcement of international contractual constraints.

\section{Introducing Contractual Constraints using Modern Contract Theory}

Cooley and Quadrini (1998) find that if firms face debt constraints, monetary policy has quantitatively important welfare effects. The economy mimics reality on a number of dimensions suggesting that indeed firms are debt constrained. Here, I think, there is need to use modern contract theory to endogenize these constraints. The issue of what is a firm, which in Arrow-Debreu theory is just a technology set, must be addressed. Here I conjecture that modeling a firm as a coalition or club is the way to proceed. Useful tools include the recursive dynamic contract theory of Thomas and Worrall (1990), Marcet and Marimon (1992,1995), and Atkeson and Lucas $(1992,1995)$. Other useful tools might be general equilibrium theory with clubs as in Cole and Prescott (1997) and financial intermediary coalitions as in Boyd and Prescott (1986).

Carlstrom and Fuerst (1997), in an interesting paper, deduce some quantitative implications of these informational constraints on contracting. Alvarez and Jermann (1998) quantitatively explore the implications of limited enforcement for asset prices in an applied general equilibrium study of asset pricing.

\section{Introducing Plant Irreversible Investment}

Marcelo Veracierto (1998) develops a method for introducing irreversible investment at the plant level into equilibrium business cycle models. The author's computational strategy makes the analysis of the class of (S,s) economies fully tractable. He finds that introducing this feature has no effects on aggregate business cycle dynamics. 


\section{Computing Equilibrium when a Distribution is part of the State Variable}

There are many issues that require a model with a distribution as a state variable. Existing tools for analyzing such model economies are limited although tools are improving. The problem is the well know curse of dimensionality in recursive analyses. Veracierto (1998) finesses this problem with his approach. Krusell and Smith (1996) have developed methods to find an approximate solution that turns out to be a remarkably good approximation in some applications.

\section{Role of Financial Costly Financial Intermediation in Business Cycle}

Large amounts of resources are used in financial intermediation. In the United States resources used are approximately 9 percent of GNP. The average spread between average bor-

rowing and average lending rates is about 5 percent. Further there is a lot of borrowing and lending between households that is intermediated through the business sector. In the United States, governments have nominal liabilities equal to about one annual GNP.

\section{The Role of Varying Number of Shifts that Plants are Operated}

A margin of adjustment that has not been introduced into any applied general equilibrium analysis of business cycles is the option to vary the number of shifts a plant is operated. This is an important margin of adjustment in the automobile industry. 


\section{References}

Only references not appearing in Cooley, T. F. (1995), Frontiers of Business Cycle Research, Princeton University Press, Princeton, N. J. are listed below.

Alvarez, F. and U. Jermann (1998), Asset pricing when risk sharing is limited by default, mimeo.

Atkeson, A. and R. Lucas (1992), On efficient distribution with private information, Review of Economic Studies, 59(3): 427-53.

Atkeson, A. and R. Lucas (1995), Efficiency and equality in a simple model of efficient unemployment insurance, Journal of Economic Theory, 66(1): 64-88.

Baxter, M. and M. Crucini (1995), Business cycles and the asset structure of foreign trade, International Economic Review, 36(4): 821-54.

Boyd, J. and E. Prescott (1986), Financial intermediary-coalitions, Journal of Economic Theory, 38(2): 211-32.

Bresnahan, T. and V. Ramey (1993), Segment shifts and capacity utilization in the U.S. automobile industry, American Economic Review, 83(2): 213-18.

Brock, W. and L. Mirman (1972), Optimal economic growth and uncertainty: the discounted case, Journal of Economic Theory, 4(3): 479-513.

Carlstrom, C. and T. Fuerst (1997), Agency costs, net worth, and business fluctuations: a computable general equilibrium analysis, American Economic Review, 87(5): 893-910.

Cass, D. (1965), Optimum growth in an aggregative model of capital accumulation, Review of Economic Studies, 32(3): 233-40.

Chari, V.V., P. Kehoe and E. McGrattan (1998), Sticky price models of the business cycle: can the contract multiplier solve the persistence problem?, Federal Reserve Bank of Minneapolis Staff Report 217. 
Chari, V.V., P. Kehoe and E. McGrattan (1998), Monetary shocks and real exchange rates in sticky price models of international business cycles, Federal Reserve Bank of Minneapolis Staff Report 223.

Christiano, L. and M. Eichenbaum (1995), Liquidity effects, monetary policy, and the business cycle, Journal of Money, Credit and Banking, 27(4): 1113-36.

Christiano, L. and M. Eichenbaum (1997), Sticky price and limited participation models of money: a comparison, European Economic Review, 41(6): 1201-49.

Cole, H. and E. Prescott (1997), Valuation equilibrium with clubs, Journal of Economic Theory, 74(1): 19-39.

Cooley, T., G. Hansen, and E. Prescott (1995), Equilibrium business cycle with idle resources and variable capacity utilization, Economic Theory, 6(1): 35-49.

Cooley, T., and V. Quadrini (1998), Monetary policy and the financial decisions of firms, mimeo.

Devereux, M., A. Head, and B. Lapham, (1996), Aggregate fluctuations with increasing returns to specialization and scale, Journal of Economic Dynamics and Control, 20(4): 627-56.

Diamond, P. (1965), National debt in a neoclassical growth model, American Economic Review, 55(5): 1126-50.

Fagnart, J., O. Licandro, and F. Portier (1997), Firm heterogeneity, capacity utilization and the business cycle, mimeo.

Fitzgerald, T. (1996) Reducing working hours, Economic Review, Federal Reserve Bank of Cleveland, 32(4): 13-22.

Fitzgerald, T. (1998), Work schedules, wages, and employment in a general equilibrium model with team production, forthcoming in Review of Economic Development. 
Freeman, S. and F. Kydland (1998), Monetary aggregates and output, mimeo.

Gollin, D. (1997), Getting income shares right: self employment, unincorporated enterprise, and the cobb-douglas hypothesis, mimeo.

Hart, O. (1979), Monopolistic competition in a large economy with differentiated commodities, Review of Economic Studies, 46(1): 1-30.

Hodrick, R. and E. Prescott (1980 and 1997), Postwar U.S. business cycles: an empirical investigation, Journal of Money, Credit, and Banking, 29(1): 1-16 (1997), Discussion Paper 451, Northwestern University (1980).

Hornstein, A. and J. Praschnik (1997), Intermediate inputs and sectoral comovement in the business cycle, Journal of Monetary Economics, 40(3): 573-95.

Ireland, P. (1995), Endogenous financial innovation and the demand for money, Journal of Money, Credit and Banking, 27(1): 107 - 23.

Johnson, H. (1960), The cost of protection and the scientific tariff, The Journal of Political Economy, 68(4): 327-45.

Jones, L. (1984), A competitive model of commodity differentiation, Econometrica, 52(2): 50730.

Kehoe, T. and D. Levine (1993), Debt constrained asset markets, Review of Economic Studies, 60(4): $865-88$.

Kehoe, P. and F. Perri (1998), International business cycles with endogenous market incompleteness, Federal Reserve Bank of Minneapolis, mimeo.

Kehoe, T. and E. Prescott (1995), Introduction to the symposium: the discipline of applied general equilibrium, Economic Theory, 6(1): 1-11. 
Kollmann, R. (1996), Incomplete asset markets and the cross-country consumption correlation puzzle, Journal of Economic Dynamics and Control, 20(5): 945-61.

Koopmans, T. (1965), On the concept of optimal growth, The Econometric Approach to Development Planning, Rand McNally, Chicago.

Kravis, I. (1959), Relative income shares in fact and theory, American Economic Review, 49(5): 917-49.

Krusell, P. and A. Smith (1996), Income and wealth heterogeneity in the macroeconomy, mimeo.

Kydland, F. and E. Prescott (1982), Time to build and aggregate fluctuations, Econometrica, 50(6): 1345-70.

Kydland, F. and E. Prescott (1996), The computational experiment: an econometric tool, Journal of Economic Perspectives, 10(1): 69-85.

Lucas, R. (1997), Understanding business cycles, Journal of Monetary Economics, 5(0): 7-29.

Lucas, R. (1980), Equilibrium in a pure currency economy, Economic Inquiry, 18(2): 203-20.

Lucas, R. (1981), Studies in Business-Cycle Theory, MIT Press, Cambridge, MA.

Mas-Colell, A. (1975), A model of equilibrium with differentiated commodities, Journal of Mathematical Economics, 2: 263-96.

McCallum, B. and M. Goodfriend (1987), Money: theoretical analysis of the demand for money, NBER Working Paper No. 2157.

Prescott, E. and R. Townsend (1984), Pareto optima and competitive equilibria with adverse selection and moral hazard, Econometrica, 52(1): 21-45.

Saving, T. (1971), Transaction costs and the demand for money, American Economic Review, 61(3): 407-20. 
Scheinkman, J. and L. Weiss (1986), Borrowing constraints and aggregate economic activity, Econometrica, 54(1): 23-45.

Schreft, S. (1992), Transaction costs and the use of cash and credit, Economic Theory, 2(2): 28396.

Schumpeter, J. (1954), A History of Economic Analysis, Oxford University Press, New York.

Thomas, J. and T. Worrall (1990), Income fluctuations and asymmetric information: an example of a repeated principal-agent problem, Journal of Economic Theory, 51(2): 367-90.

Townsend, R. M. (1979), Optimal contracts and competitive markets with costly state verification, Journal of Economic Theory, 21(2): 265-93.

Veracierto, M. (1998), Plant level irreversible investment and equilibrium business cycles, mimeo. 